\title{
VARIACIÓN MORFOLÓGICA DE SEMILLAS DE Taxus globosa Schltdl. PROVENIENTES DE DOS REGIONES GEOGRÁFICAS DE MÉXICO
}

\author{
MORPHOLOGICAL VARIATION OF Taxus globosa Schltdl. SEEDS COLLECTED FROM TWO \\ GEOGRAPHICAL REGIONS OF MÉXICO
}

\author{
Susana E. Ramírez-Sánchez ${ }^{1 *}$, Javier López-Upton ${ }^{2}$, Gabino García de los Santos ${ }^{1}$, J. Jesús Vargas-Hernández², \\ Adrián Hernández-Livera ${ }^{1}$ y Óscar J. Ayala-Garay ${ }^{1}$
}

\begin{abstract}
${ }^{1}$ Postgrado en Recursos Genéticos-Producción de Semillas y ${ }^{2}$ Postgrado Forestal, Colegio de Postgraduados-Campus Montecillo. Km 36.5. Carr. México-Texcoco. 56230, Texcoco, Edo de México. Tel. 01 (595) 9520200 ext. 1463.

*Autor para correspondencia (eramirez@colpos.mx)
\end{abstract}

\section{RESUMEN}

Taxus globosa Schltdl. es la única especie del género Taxus que se encuentra en México y está protegida por el Gobierno Mexicano. Su corteza y hojas contienen taxol, un compuesto de gran valor por su función como anticancerígeno. Su regeneración natural es por semillas que germinan de manera escasa y presentan latencia. El presente estudio se hizo para conocer la variación morfológica existente en las semillas de Taxus globosa y determinar si la latencia es causada por algún factor físico. Se utilizaron semillas procedentes de dos regiones de México: norte (Nuevo León) y centro (Hidalgo y Querétaro). Se midieron las dimensiones de la semilla (largo, ancho, área, perímetro y proporción embrión-megagametofito) mediante análisis de imagen, así como peso volumétrico y peso de 1000 semillas. Para evaluar las características físicas de la testa, las semillas se sometieron a una prueba de escarificacion con ácido sulfúrico durante 5, 10, 15, 20, 25 y 30 min seguida de una prueba de viabilidad con tetrazolio; también se midió la dureza de la testa y la velocidad de imbibición. Se encontraron diferencias geográficas en el tamaño de la semilla ( $28 \%$ más grande $(\mathrm{P} \leq \mathbf{0 . 0 5})$ en la región norte). La proporción de embrión-megagametofito fue de sólo $4 \%$ en el norte y de $3 \%$ en el centro; la semilla de ambas regiones sólo soportó 5 min en $\mathrm{H}_{2} \mathrm{SO}_{4}$, y la testa en las semillas del norte es más dura que en las del centro (1.29 vs. 0.86 $\mathrm{kg} \mathrm{cm}^{-2}$ ). La semilla del norte absorbe más agua que la del centro. La semilla no necesita escarificación para ablandar la testa. El embrión en T. globosa se considera subdesarrollado y posible causa de la latencia de la semilla.

Palabras clave: Taxus globosa, dureza de testa, imbibición, variación morfológica.

\section{SUMMARY}

Taxus globosa Schltdl. is the only species of the genus Taxus that grows in Mexico and is protected by the Mexican government. Its bark and leaves contain taxol, a high value compound used as a cancer drug. Natural regeneration of Taxus globosa is by seeds which germinate scarcely and present dormancy. The present study was done in order to determine the morphological variation of Taxus globosa seeds and to learn if seed dormancy is caused by physical factors. Collected seeds from northern (Nuevo León) and central (Hidalgo and Queretaro) México were used to measure seed dimensions (length, width, area, perimeter and embryo/megagametophyte ratio) by image analysis, in addition to volumetric weight, and weight of 1000 seeds. To evaluate the physical characteristics of the seed coat, a scarification test with sulfuric acid for $5,10,15,20,25$ and $30 \mathrm{~min}$ was done followed a tetrazo- lium viability test. Seed coat hardness and imbibition rate were also measured. There were differences in seed size betwee geographical origins $(28 \%$ bigger in the northern region). The embryo/megagametophyte ratio of was only $4 \%$ in seeds from the northern region and $3 \%$ in the central region. Seeds of both regions only supported 5 min immersed in $\mathrm{H}_{2} \mathrm{SO}_{4}$, and seeds from the northern region were harder $\left(1.29 v s .0 .86 \mathrm{~kg} \mathrm{~cm}^{-2}\right)$. Seeds from the northern absorbed more water than those from the central region. Taxus globosa seeds do not need scarification to soften the seed coat, and the possible cause of seed dormancy appears to be their undeveloped embryos.

Index words: Taxus globosa, hardness of seed coat, imbibition, morphological variation.

\section{INTRODUCCIÓN}

Taxus globosa Schltdl., comúnmente llamado tejo, romerillo o granadillo, es la única especie del género Taxus que se encuentra en México. La corteza y hojas de esta conífera contienen taxol (Shemluck et al., 2003), una sustancia útil en el tratamiento de varios tipos de cáncer (Barquero, 2007; Soto et al., 2000). El gobierno mexicano considera a T. globosa en la categoría de especie rara para su protección por lo restringido de su distribución natural (SEMARNAT, 2002). Habita en bosques mesófilo de montaña y de pino en zonas aisladas, barrancas húmedas y pendientes pronunciadas (Zavala, 2001), en los Estados de Nuevo León, Tamaulipas, San Luis Potosí, Querétaro, Hidalgo, Veracruz, Oaxaca y Chiapas en México; también se encuentra en Guatemala, El Salvador y Honduras (Zamudio, 1992; Shemluck et al., 2003). A pesar de su importancia ecológica y medicinal, existen pocos estudios de T. globosa en los que se aborden aspectos de demografía en una localidad (Zavala, 2002), contenido de taxol en corteza y hojas (Soto et al., 2000) o germinación de la semilla (Zavala, 2001; Nicholson y Munn, 2003). Se ha tratado infructuosamente de reproducirla por semilla (Zavala, 2001; Nicholson et al., 2003), 
y sólo se ha tenido éxito con métodos vegetativos (Muñoz et al., 2009).

La función primordial de la semilla en cualquier especie es producir nuevos individuos. La variación en el tamaño de la semilla se considera importante porque puede proporcionar a la plántula la habilidad para establecerse en un mosaico de micrositios con condiciones bióticas y abióticas diversas (Bonfil, 1998). Se ha reportado que la semilla de T. globosa presenta latencia (Zavala, 2001; Shemluck et al., 2003), característica que según Bewley y Black (1994) puede ser de origen mecánico, fisiológico o morfológico. Según Masa-Aki et al. (2007), el conocimiento de la anatomía de la semilla de cualquier especie puede proporcionar información sobre las causas de la latencia y cómo eliminarla. $\mathrm{Si}$ bien en otras especies del género Taxus se han encontrado embriones inmaduros (Forbis et al., 2002), en T. globosa no se han hecho estudios anatómicos que confirmen dicha aseveración, y la descripción disponible de la anatomía de su semilla es muy general. En poblaciones de la región de Mineral del Chico, Hidalgo, Zavala (2002) midió el peso de la semilla en diferentes grados de madurez.

El tamaño de la semilla se correlaciona positivamente con la germinación y el crecimiento de las plántulas en algunas especies forestales, pues las semillas grandes logran un mayor incremento inicial en altura que las obtenidas de semillas pequeñas, debido a que poseen más tejido de reserva como fuente de alimento inicial para el embrión, y proveen nutrientes por más tiempo (Bonfil, 1998). Stanton (1984) menciona que las semillas grandes de algunas especies forestales pueden germinar más y con mayor vigor que las pequeñas. En especies maderables como Cecropia obtusifolia Bertol (Tenorio-Galindo et al., 2008) y no maderables como Stenocerus beneckei (Ehrenb.) Buxb. (Ayala-Cordero et al., 2004) se encontró variación en tamaño y peso de semillas fisiológicamente maduras, variación que tiene repercusiones tanto ecológicas como económicas. MuniveMartínez et al. (2008) analizaron la variación de semillas en
Pinus ayacahuite var. veitchii Shaw, mediante variables de peso, longitud y ancho; encontraron diferencias significativas entre regiones y concluyeron que estas características sirven como base para incrementar el tamaño de la semilla mediante mejoramiento genético.

En el caso del T. globosa, se propone usar el tamaño de la semilla como una estrategia de selección temprana para un programa de mejoramiento genético. Por lo anterior, el presente trabajo se realizó con el objetivo de comparar las características morfológicas externas e internas de la semilla de Taxus globosa proveniente de dos regiones geográficas de México y cuantificar la dureza y grado de permeabilidad de la testa.

\section{MATERIALES Y MÉTODOS}

\section{Recolección de semilla}

La semilla se recolectó en 11 localidades, cinco de ellas en el Estado de Nuevo León, región norte, y seis en los Estados de Hidalgo y Querétaro, región centro (Cuadro 1, Figura 1). La semilla se obtuvo directamente de la copa de los árboles durante septiembre a noviembre de 2007, cuando el arilo tenía un color rojo. Las semillas colectadas fueron empaquetadas y rotuladas con datos de sitio y fecha. Se hicieron lotes masales al agrupar la semilla por región. En muestras de semillas completas tomadas al azar se hizo la evaluación morfológica de semillas con y sin arilo; en semillas sin arilo también se hizo una caracterización física y un análisis anatómico.

\section{Descripción morfológica externa de la semilla completa}

Para este análisis se utilizaron 100 semillas completas, las que fueron procesadas mediante análisis de imágenes digitales (Media Cybernetics, 1997), para comparar el arilo entre las regiones; las imágenes se obtuvieron con un escáner marca Epson $3170 \circledR$ a color, con una resolución de 2400 dpi. A las mismas semillas se les retiró el arilo y se

Cuadro 1. Ubicación de las localidades de Taxus globosa Schltdl. muestreadas.

\begin{tabular}{|c|c|c|c|c|}
\hline Localidad & Municipio, Estado & $\begin{array}{c}\text { Latitud } \\
\mathrm{N}\end{array}$ & $\begin{array}{c}\text { Longitud } \\
\mathrm{O}\end{array}$ & $\begin{array}{c}\text { Altitud } \\
\text { (m) }\end{array}$ \\
\hline \multicolumn{5}{|l|}{ Región Norte } \\
\hline El Tejocote & Santiago, N.L. & $25^{\circ} 19^{\prime} 20^{\prime \prime}$ & $100^{\circ} 15^{\prime} 30^{\prime \prime}$ & 1970 \\
\hline Cañada La Trinidad & Santiago, N.L. & $25^{\circ} 14^{\prime} 49^{\prime \prime}$ & $100^{\circ} 09^{\prime} 20^{\prime \prime}$ & 1361 \\
\hline Yerbabuena & Zaragoza, N.L. & $23^{\circ} 55^{\prime} 31^{\prime \prime}$ & $99^{\circ} 47^{\prime} 58^{\prime \prime}$ & 2100 \\
\hline La Encantada & Zaragoza, N.L. & $23^{\circ} 55^{\prime} 20^{\prime \prime}$ & $99^{\circ} 48^{\prime} 20^{\prime \prime}$ & 2385 \\
\hline La Tinaja & Zaragoza, N.L. & $23^{\circ} 53^{\prime} 25^{\prime \prime}$ & $99^{\circ} 47^{\prime} 29^{\prime \prime}$ & 2580 \\
\hline \multicolumn{5}{|l|}{ Región Centro } \\
\hline Los Granadillos & Pinal de Amoles, Qro. & $21^{\circ} 12^{\prime} 40^{\prime \prime}$ & $99^{\circ} 41^{\prime} 00^{\prime \prime}$ & 2400 \\
\hline Cañada de Agua Fría & Pinal de Amoles, Qro. & $21^{\circ} 08^{\prime} 14^{\prime \prime}$ & $99^{\circ} 41^{\prime} 06^{\prime \prime}$ & 2570 \\
\hline Los Corrales & Mineral El Chico, Hgo. & $20^{\circ} 12^{\prime} 13^{\prime \prime}$ & $98^{\circ} 43^{\prime} 33^{\prime \prime}$ & 2550 \\
\hline Los Zorrillos & Mineral El Chico, Hgo. & $20^{\circ} 13^{\prime} 16^{\prime \prime}$ & $98^{\circ} 43^{\prime} 08^{\prime \prime}$ & 2400 \\
\hline Los Ayacahuites & Mineral El Chico, Hgo. & $20^{\circ} 12^{\prime} 25^{\prime \prime}$ & $98^{\circ} 43^{\prime} 10^{\prime \prime}$ & 2630 \\
\hline Pueblo Nuevo & Mineral El Chico, Hgo. & $20^{\circ} 11^{\prime} 04^{\prime \prime}$ & $98^{\circ} 40^{\prime} 42^{\prime \prime}$ & 2530 \\
\hline
\end{tabular}




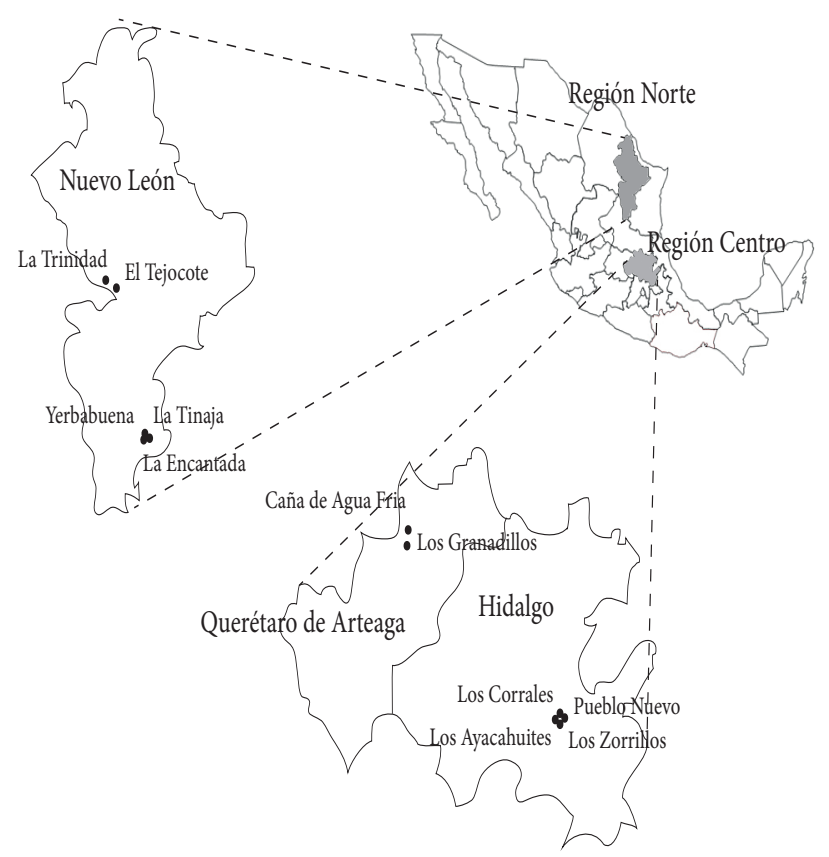

Figura 1. Ubicación geográfica de los sitios de recolección de la semilla de Taxus globosa Schltdl.

escanearon nuevamente. Con las imágenes obtenidas se determinó área, longitud, ancho y perímetro de la semilla sin arilo (García y Estrada, 1999), con apoyo del programa analizador de imágenes Image tool ${ }^{\circledR} 3.0$ para Windows.

\section{Descripción de estructuras internas de la semilla}

Para identificar las estructuras internas de la semilla se hizo una prueba topográfica de 2, 3, 5 cloruro de trifenil tetrazolio (Sigma $\left.{ }^{\circledR}\right)$ (ISTA, 2005) en una muestra de 25 semillas sin arilo y pre-acondicionadas mediante remojo en agua destilada durante $24 \mathrm{~h}$. Las semillas fueron disectadas longitudinalmente y puestas en una solución de cloruro de tetrazolio $(0.1 \%)$ durante $8 \mathrm{~h}$. Luego se colocaron bajo la lente de un microscopio estereoscópico (Olimpus ${ }^{\circledR}$ ), conectado a una computadora, para digitalizar las imágenes; se eliminó el exceso de agua para evitar brillos que pudieran afectar la imagen. De estas semillas se extirparon embriones que también fueron fotografiados.

Para estimar el área, la longitud, el ancho y el perímetro del megagametofito y del embrión, se utilizaron otras 25 semillas preacondicionadas como se indicó anteriormente y disectadas longitudinalmente; cada semilla se fotografió por separado con el procedimiento ya descrito; las imágenes obtenidas se analizaron con Image tool@ 3.0 para Windows. Con base en la cantidad total de pixeles representados por el megagamentofito y por el embrión en cada imagen, se obtuvo la proporción que representa la superficie de estas estructuras con respecto a la semilla entera.

\section{Caracterización física de la semilla}

En esta caracterización se estimó el peso de 1000 semillas (P1000S), en ocho repeticiones de 100 semillas sin arilo por cada región, según el método propuesto por ISTA (2005). Además se evaluó el peso volumétrico (PV) de semilla sin arilo, en $5 \mathrm{~mL}$ de semilla medidos con una probeta de 10 $\mathrm{mL}$, y posteriormente se valoró su masa; en este procedimiento se realizaron cuatro repeticiones por región. Los pesos se obtuvieron con una balanza analítica Ohaus ${ }^{\circledR}$.

\section{Evaluación de características físicas de la testa}

Con la finalidad de verificar las características físicas de la testa como posible barrera para la entrada de agua y salida de la radícula, se hicieron tres pruebas en las muestras de ambas regiones. La primera prueba consistió en la escarificación con ácido sulfúrico concentrado $\left(\mathrm{H}_{2} \mathrm{SO}_{4}\right.$, grado reactivo), a dos repeticiones de 25 semillas, con tiempos de $0,5,10,15,20,25$ y $30 \mathrm{~min}$; posteriormente se verificó la viabilidad de la semilla con una prueba de tetrazolio (ISTA, 2005). La segunda prueba fue la evaluación de la dureza en lotes de 25 semillas con cuatro repeticiones, mediante un texturómetro Universal marca Force Five Mod FDV-30®, en $\mathrm{kg} \mathrm{cm}^{-2}$. La tercera fue una prueba de imbibición en una muestra de 50 semillas con dos repeticiones; las semillas se colocaron en $200 \mathrm{~mL}$ de agua destilada, volumen que se mantuvo constante a una temperatura entre 15 y $23{ }^{\circ} \mathrm{C}$, y el peso total de las muestras se registró cada $24 \mathrm{~h}$ en una balanza analítica.

\section{Análisis estadístico}

Las variables de caracterización física, como el peso de 1000 semillas y el peso volumétrico, así como las de la caracterización morfológica, se analizaron por medio de la prueba de $\mathrm{t}$ de Student, con muestras apareadas y $\alpha=$ 0.01, con el programa XLSTAT (http://www.xlstat.com/) complemento de EXCEL. Para la comparación entre regiones geográficas en cuanto a las características de la testa, se utilizó un análisis de varianza y una prueba de Tukey con el programa estadístico SAS ${ }^{(}$(Sas Institute, 1998). Los datos de la curva de imbibición, que mostraron la cinética de entrada del agua en la semilla, se analizaron mediante una regresión logarítmica con respecto al tiempo, con su respectiva $\mathrm{R}^{2}$.

\section{RESULTADOS Y DISCUSIÓN}

\section{Descripción morfológica externa de la semilla completa}

La semilla madura de $T$. globosa está cubierta por un arilo carnoso y mucilaginoso de color rojo (Figura 2), con una abertura en su parte inferior por la cual se puede ver la semilla; una vez retirado el arilo se observa a la semilla 


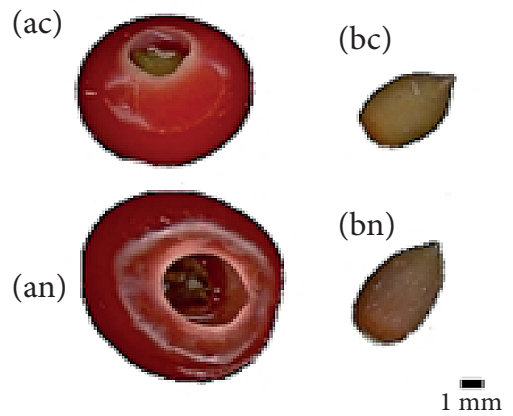

Figura 2. Semilla completa de T. globosa (con arilo) de la región centro (ac) y región norte (an). Semilla de T. globosa sin arilo, de la región centro (bc) y norte (bn).

Cuadro 2. Comparación de medias (T de Student) de las variables de morfología externa en la semilla de dos regiones de Taxus globosa Schltdl. de México.

\begin{tabular}{|c|c|c|c|c|c|}
\hline \multirow[t]{2}{*}{ Variables } & \multicolumn{2}{|c|}{ Región Norte } & \multicolumn{2}{|c|}{ Región Centro } & \multirow{2}{*}{$\begin{array}{l}\text { Signifi- } \\
\text { cancia } \\
\text { entre } \\
\text { regiones }\end{array}$} \\
\hline & Promedio & CV (\%) & Promedio & CV (\%) & \\
\hline \multicolumn{6}{|l|}{ Semilla completa } \\
\hline Área $\left(\mathrm{mm}^{2}\right)$ & 77.48 & 19.61 & 64.61 & 17.40 & ** \\
\hline Longitud (mm) & 10.37 & 9.85 & 9.53 & 8.88 & $* *$ \\
\hline Ancho (mm) & 9.54 & 13.47 & 8.81 & 9.48 & $* *$ \\
\hline Perímetro (mm) & 36.32 & 9.93 & 33.03 & 9.48 & $* *$ \\
\hline \multicolumn{6}{|l|}{ Semilla sin arilo } \\
\hline Área $\left(\mathrm{mm}^{2}\right)$ & 23.82 & 9.62 & 19.15 & 12.32 & $* *$ \\
\hline Longitud (mm) & 6.57 & 7.81 & 6.18 & 11.64 & $* *$ \\
\hline Ancho (mm) & 4.72 & 6.53 & 4.04 & 10.83 & $* *$ \\
\hline Perímetro (mm) & 19.79 & 6.75 & 17.85 & 10.84 & $* *$ \\
\hline
\end{tabular}

${ }^{* *}$ Diferencias con nivel de probabilidad de $0.01 ; \mathrm{CV}=$ coeficiente de variación.

desnuda. Las imágenes obtenidas permitieron analizar las semillas de manera rápida y confiable, en las cuales se detectaron diferencias significativas entre regiones (Cuadro $2)$, ya que las provenientes de la región norte superaron $(\mathrm{P} \leq 0.05)$ a las del centro, en todas las variables medidas, tanto en semillas con arilo como sin arilo. Estas diferencias se atribuyen al aislamiento geográfico que existe entre las poblaciones, que pudo haber ocasionado un proceso de diferenciación morfológica, como se ha demostrado en otras especies (Mápula-Larreta et al., 2007; Mehes et al., 2009).

El reducido tamaño de las poblaciones de la región centro del país (Hidalgo y Querétaro), puede estar ocasionando endogamia y, por tanto, reducción en el tamaño de las semillas, como la reportada por Mosseler et al. (2000). En estas especies se ha encontrado que las poblaciones de sitios más extremosos, como es el caso de las semillas del norte de México que generalmente producen semillas de mayor tamaño como un mecanismo para aumentar la cantidad de reservas (Donahue y López-Upton, 1996; Mapula-Larreta et al., 2007). Lo anterior podría indicar que las semillas del norte generan plantas más vigorosas (Stanton, 1984). T. globosa podría estar en un proceso de sub-especiación o extinción, ya que el flujo génico disminuye y provoca cambios genéticos que pueden beneficiar o no a la especie (Ledig, 1986). Para corroborar lo anterior es necesario realizar estudios ecológicos más detallados así como de genética de poblaciones.

\section{Descripción de la morfología interna de la semilla}

En las proporciones que representan el megagametofito y el embrión con respecto a la semilla completa no se encontraron diferencias significativas entre regiones. En otros estudios con especies del género Taxus se ha observado que el embrión ocupa $10 \%$ del total de la semilla (Forbis et al., 2002). En el presente estudio los embriones de T. globosa representan sólo 3 y $4 \%$ del tamaño de la semilla, respectivamente, en las regiones centro y norte del país (Cuadro 3 ), por lo que se puede inferir que el embrión en T. globosa es pequeño y subdesarrollado. Forbis et al. (2002) reportan que el embrión del género Taxus es el más pequeño de las gimnospermas. Esta característica puede estar relacionada con el tipo de latencia que presenta la semilla, ya que si el embrión no está completamente desarrollado hasta el punto en que ocupe la longitud total de la semilla y sea capaz de romper la testa para emerger, no logrará germinar; esto coloca a T. globosa como una especie con latencia morfológica, que según Forbis et al. (2002) ocurre en especies poco evolucionadas a las que llama plantas ancestrales.

En las variables de área, largo, ancho y perímetro de las semillas (Cuadro 3$)$ se encontraron diferencias $(P \leq 0.01)$ entre ambas regiones. Si estas diferencias tienen relación con procesos biológicos como germinación, crecimiento y desarrollo de plántulas, podrían servir como base para el establecimiento de una estrategia de selección temprana. Sin embargo, estos resultados son preliminares y se requieren más estudios para determinar si el tamaño de la semilla es una característica importante para la supervivencia de las poblaciones de esta especie.

\section{Descripción de estructuras internas de la semilla}

La semillade T. globosa, como gimnosperma que es, posee tres estructuras básicas: testa, megagametofito y embrión (Figura 3). La parte externa de la testa está compuesta por una serie de capas de tejido, presumiblemente exotesta, mesotesta y endotesta, que al absorber agua se desprenden fácilmente; bajo estas capas se encuentra la testa lignificada. El megagametofito, de consistencia granulosa y color blanco, se encuentra protegiendo al embrión cuyo tejido blanco es de una textura más consistente que el del 
Cuadro 3. Comparación de medias (t de Student) de las variables de morfología interna en semillas de dos regiones de T. globosa Schltdl. de México.

\begin{tabular}{|c|c|c|c|c|c|}
\hline \multirow[b]{2}{*}{ Variables } & \multicolumn{2}{|c|}{ Región Norte } & \multicolumn{2}{|c|}{ Región Centro } & \multirow{2}{*}{$\begin{array}{l}\text { Signifi } \\
\text { cancia }\end{array}$} \\
\hline & Promedio & $\mathrm{CV}(\%)$ & Promedio & $\mathrm{CV}(\%)$ & \\
\hline \multicolumn{6}{|c|}{ Megagametofito } \\
\hline Área $\left(\mathrm{mm}^{2}\right)$ & 12.49 & 12.74 & 9.07 & 18.14 & ** \\
\hline Longitud (mm) & 4.60 & 5.81 & 4.08 & 11.76 & ** \\
\hline Ancho $(\mathrm{mm})$ & 3.49 & 7.77 & 2.85 & 8.65 & ** \\
\hline Perímetro (mm) & 17.87 & 17.71 & 12.75 & 16.95 & ** \\
\hline \multicolumn{6}{|l|}{ Embrión } \\
\hline Área $\left(\mathrm{mm}^{2}\right)$ & 0.76 & 0.21 & 0.57 & 0.26 & ** \\
\hline Longitud (mm) & 1.92 & 0.12 & 1.70 & 0.17 & ** \\
\hline Ancho $(\mathrm{mm})$ & 0.57 & 0.11 & 0.47 & 0.15 & $* *$ \\
\hline Perímetro (mm) & 4.65 & 0.13 & 4.15 & 0.18 & ns \\
\hline \multicolumn{6}{|c|}{ Proporción respecto a la semilla completa (\%) } \\
\hline Embrión & 3.23 & 17.42 & 4.4 & 15.07 & ns \\
\hline Megagametofito & 58.11 & 5.24 & 57.81 & 6.74 & ns \\
\hline
\end{tabular}

${ }^{*}$ Significativo con nivel de probabilidad de $0.01 ; \mathrm{ns}=$ no significativo.

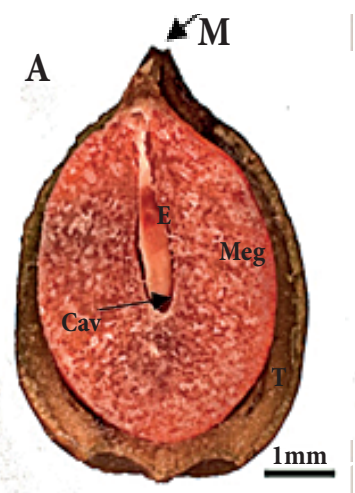

B

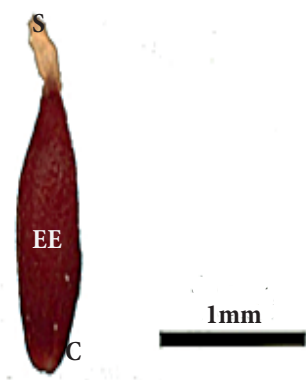

Figura 3. Corte longitudinal de semilla (A) de Taxus globosa Schltdl. procesada con cloruro de tetrazolio. $\mathrm{T}=$ testa; $\mathrm{M}=$ micrópilo; $\mathrm{Meg}=$ megagametofito; Cav = cavidad embrionaria; $\mathrm{E}=$ embrión; $\mathrm{B}=$ Embrión disectado $\mathrm{y}$ teñido con cloruro de tetrazolio; $\mathrm{S}=$ suspensor; $\mathrm{EE}=$ eje embrionario ; $\mathrm{C}$ $=$ cotiledones.

megagametofito y posee un suspensor que difícilmente se tiñe al ponerse en contacto con la solución de tetrazolio, por ser tejido muerto.

\section{Caracterización física de la semilla}

El peso de 1000 semillas fue mayor en las provenientes de la región norte (Cuadro 4). Datos similares se han observado en otras especies; por ejemplo en Pseudotsuga menziesii (Mirb) Franco en la que Mápula-Larreta et al. (2007) reportaron mayor peso de conos y semillas en poblaciones de Chihuahua, Coahuila y Nuevo León que en las de Veracruz, Hidalgo y Puebla.

En coníferas como Pinus montícola Douglas ex. D. Don. y P. strobus L., se ha encontrado reducción del peso de las semillas en poblaciones de Canadá, atribuida a la fragmen- tación del hábitat ya que ésta disminuye el flujo génico y reduce la diversidad genética (Mehes et al., 2009). En México, Donahue y López-Upton (1996) y Juárez et al. (2006) encontraron amplias diferencias entre poblaciones del norte y centro del país en las características morfológicas de conos, semillas, hojas y plántulas de Pinus greggii Engelm. y Pseudotsuga menziesii, diferencias que fueron atribuidas a la fragmentación del hábitat, al tamaño reducido de las poblaciones y a la deriva génica, condiciones que pueden reducir el tamaño de las semillas. Esto se observó aquí en las áreas de estudio, ya que las poblaciones del centro se constituyen con 10 a 200 individuos mientras que en la región norte poseen de 1000 a 5000 individuos por población; la fragmentación del hábitat puede estar ocurriendo en la región centro, ya que las poblaciones de T. globosa están conformadas por pequeños manchones de árboles en cañadas contiguas en la zona, particularmente en el Estado de Hidalgo.

Cuadro 4. Caracteres físicos de la semilla de Taxus globosa Schltdl. procedente de dos regiones geográficas de México.

\begin{tabular}{lcccccc}
\hline Región & P1000S (g) & $\begin{array}{c}\mathrm{CV} \\
(\%)\end{array}$ & PV $\left(\mathrm{kg} \mathrm{hL}^{-1}\right)$ & $\begin{array}{c}\mathrm{CV} \\
(\%)\end{array}$ & $\begin{array}{c}\text { Dureza } \\
\left(\mathrm{kg} \mathrm{cm}^{-2}\right)\end{array}$ & $\begin{array}{c}\mathrm{CV} \\
(\%)\end{array}$ \\
\hline Norte & $44.31 \mathrm{a}$ & 2.63 & $45.95 \mathrm{~ns}$ & 5.45 & $1.295 \mathrm{a}$ & 0.13 \\
Centro & $34.87 \mathrm{~b}$ & 4.25 & $47.05 \mathrm{~ns}$ & 2.13 & $0.866 \mathrm{~b}$ & 0.42 \\
DMS & 0.124 & \multicolumn{5}{c}{0.403} \\
\hline
\end{tabular}

Melzack y Watts (1982) reportaron un peso de $56.6 \mathrm{~g}$ por 1000 semillas para Taxus baccata L. en la región oriental de Inglaterra, y consideraron que las semillas de esta zona son más pequeñas que las de Polonia y Holanda, cuyos valores son de $59 \mathrm{~g} \mathrm{y} 77 \mathrm{~g}$ por 1000 semillas, respectivamente. Las semillas del centro de México (34.9 g) están por debajo de los valores reportados hasta ahora para Taxus.

La semilla presenta su más alto nivel de vigor y potencial germinativo cuando alcanza la madurez fisiológica. En este estado la semilla tiene el máximo peso seco por haber acumulado la máxima cantidad de reservas nutritivas, y presumiblemente el embrión ha completado su desarrollo. Por ello, una semilla relativamente pequeña con un alto valor de peso volumétrico, tiene igual calidad fisiológica que una semilla relativamente grande (Rodríguez et al., 1998). En este estudio se encontró que las semillas de la región centro tienen un peso volumétrico ligeramente mayor que las de la región norte (47.05 vs. $\left.45.96 \mathrm{~kg} \mathrm{hL}^{-1}\right)$, pero sin diferencias estadísticas $(\alpha=0.01)$; se puede concluir que la semilla del centro tiene igual calidad fisiológica que la semilla del norte. Sin embargo, para este estudio no se realizaron pruebas de vigor ni de capacidad germinativa. 


\section{Características físicas de la testa}

En la prueba de escarificación con ácido sulfúrico concentrado $\left(\mathrm{H}_{2} \mathrm{SO}_{4}\right.$, grado reactivo) a distintos tiempos, se encontró que la semilla no soporta un tiempo mayor a 5 min (Cuadro 5), puesto que en periodos más prolongados pierde viabilidad. Este dato proporciona un primer indicio de que la testa no es obstáculo para la germinación, pues se logró romper y permitir la imbibición; es decir, la falta de germinación ocurrió por razones inherentes al embrión. En el género Prosopis D’Aubeterre et al. (2002) reportaron un alto porcentaje de germinación al aplicar $\mathrm{H}_{2} \mathrm{SO}_{4}$ a la semilla durante 5 o $10 \mathrm{~min}$. En contraste, la semilla de T. globosa de las dos regiones mexicanas sólo soportó la inmersión en ácido sulfúrico por 5 min sin perder viabilidad. No obstante, se encontraron diferencias $(\mathrm{P} \leq 0.01)$ entre regiones en dureza de la semilla (Cuadro 4), ya que las semillas del norte superaron a las del centro $\left(1.29 v s .0 .86 \mathrm{~kg} \mathrm{~cm}^{-2}\right)$.

Cuadro 5. Tratamiento de escarificación con $\mathrm{H}_{2} \mathrm{SO}_{4}$ en semilla de Taxus globosa Schltdl. procedente de dos regiones de México.

\begin{tabular}{cll}
\hline Tratamiento (tiempo en minutos) & Región Norte & Región Centro \\
\hline Testigo & Viable & Viable \\
5 & Viable & Viable \\
10 & No viable & No viable \\
15 & No viable & No viable \\
20 & No viable & No viable \\
25 & No viable & No viable \\
30 & No viable & No viable \\
\hline
\end{tabular}

En condiciones naturales, las semillas con cubiertas muy duras germinan sólo hasta que la testa se ablanda, lo que se consigue a través de su degradación bioquímica por digestión animal, por acción de microorganismos habitantes naturales del ambiente o por los efectos físicos del pisoteo (Moreno et al., 2006). Se esperaría entonces que la testa no sea un impedimento ni para la entrada del agua ni para la emisión de la radícula. Algunas semillas de otras especies son impermeables al agua. T. globosa no parece tener ese problema, ya que sus semillas mostraron imbibición plena con sólo 24 h de remojo (Figura 4). El patrón de imbibición fue similar entre las dos regiones, aunque las semillas de la región norte absorben agua en menos tiempo; a las 132 $\mathrm{h}$ se detiene la imbibición, para las dos regiones. También se puede inferir que el potencial hídrico de la semilla es lo suficientemente bajo para permitir la entrada del agua en el proceso de imbibición.

El grosor de la testa y el número de capas de células que la componen juegan un papel importante en el proceso de absorción de agua (Domínguez-Domínguez et al., 2007). La semilla de T. globosa cuenta con varias capas de cutícula que forman la exotesta, y en esta investigación se observó que además de absorber agua, también la retienen.

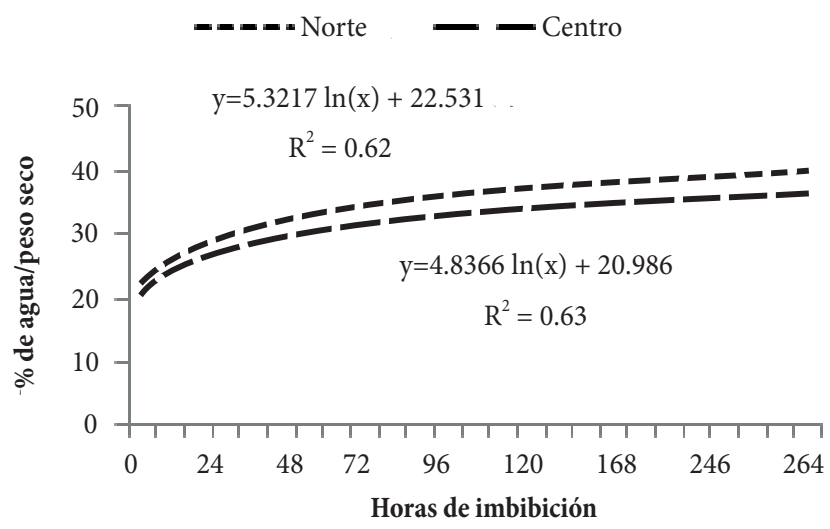

Figura 4. Curva de imbibición de semillas de Taxus globosa Schltdl. provenientes de dos regiones geográficas de México.

El papel de la testa es fundamental en la incorporación de agua por la semilla; ésta y su permeabilidad están relacionadas con el intercambio gaseoso (Bewley y Black, 1994). El efecto de la testa sobre el embrión puede ser químico por ejemplo, por la presencia de inhibidores fenólicos o mecánico al impedir el flujo necesario de agua y oxígeno para la germinación (Moreno et al., 2006). De acuerdo con la curva de imbibición obtenida, a partir de las $24 \mathrm{~h}$ aumentó la entrada de agua, lo que permite deducir que la testa de Taxus globosa no impide la absorción de agua. Por ello, la latencia de la semilla reportada por Nicholson y Munn (2003) probablemente se deba a que el embrión está subdesarrollado o inmaduro.

\section{AGRADECIMIENTOS}

Al CONACyT, por el financiamiento otorgado al proyecto 2004-C01-29/A1

\section{CONCLUSIONES}

Las variables morfológicas y las características físicas analizadas de la semilla de Taxus globosa muestran diferencias significativas entre regiones geográficas, ya que las del norte de México son mayores que las del centro. Se postula que esta especie presenta un embrión subdesarrollado o latencia de tipo morfológico, que dificulta la germinación de la semilla. Las semillas provenientes de ambas regiones no requieren de escarificación, ya que no poseen una testa dura impermeable al agua. 


\section{BIBLIOGRAFÍA}

Ayala-Cordero G, T Terrazas, L López-Mata, C Trejo (2004) Variación en el tamaño y peso de las semilla y su relación con la germinación en una población de Stenocereus beneckei. Interciencia 29:692697.

Barquero A (2007) Plantas sanadoras: pasado, presente y futuro. Rev. Quím.Viva 6:19-35.

Bewley J D, M Black (1994) Seeds: Physiology of Development and Germination. Plenum Press, New York. 445 p.

Bonfil C (1998) The effects of the seed size, cotyledon reserves, and herbivory on seedling survival and growth in Quercus rugosa and Quercus laurina (Fagaceae). Amer. J. Bot. 85:79-87.

D’Aubeterre R, J Principal, J García (2002) Effect of different scarification methods on the germination of three species of the Prosopis genera. Rev. Científica 12:575-577.

Domínguez-Domínguez S, A Domínguez-López, A González-Huerta, S Navarro-Galindo (2007) Cinética de imbibición e isotermas de adsorción de humedad de la semilla de jamaica (Hibiscus sabdarifa L.) Rev. Mex. Ing. Quím. 3:309-316.

Donahue J K, J López-Upton (1996) Geographic variation in leaf, cone and seed morphology of Pinus greggii Engelm. in native forest. For. Ecol. Manage. 82:145-157.

Forbis T A, S K Floyd, A Queiroz (2002) The evolution of embryo size in angiosperms and other seed plants: implications for the evolution of seed dormancy. Evolution 56:2112-2125.

García de los Santos G, A J Estrada G (1999) Caracterización de frijol de la variedad Bayomex mediante descriptores agronómicos y análisis de imágenes de morfología de semillas. Rev. Fitotec. Mex. 22:63-74.

ISTA, International Seed Testing Association (2005) Handbook on Tetrazolium Testing. Zurich. Switzerland. $100 \mathrm{p}$.

Juárez A A, J López-Upton, J J Vargas-Hernández, C Sáenz-Romero (2006) Variación geográfica en la germinación inicial de plántulas de Pseudotsuga menziesii de México. Agrociencia 40:783-792.

Ledig F T (1986) Conservation strategies for forest gene resources. For. Ecol. Manage. 14:77-90

Mápula-Larreta M, J López-Upton, J J Vargas-Hernández, A Hernández-Livera (2007) Reproductive indicators in natural populations of Douglas-fir in Mexico. Biodiv. Conserv. 16:727-742.

Masa-Aki O, L S Stone, J J Harada (2007) Genetics control of seed development and seed mass. In: Seed Development, Dormancy and Germination. K Bradford, H Nonogaki (eds). Annu. Plant Rev. 27:1-24.

Media Cybernetics (1997) Image Pro Plus, versión 3.1. Sprinfield, MD, USA. 534 p.

Mehes M, K Kabwe-Nkongolo, P Michael (2009) Assessing genetic diversity and structure of fragmented populations of eastern white pine (Pinus strobus) and western white pine (P. monticola) for conservation management. J. Plant Ecol. 2:143-151.

Melzack R, D Watts (1982) Variations in seed weigth, germination, and seedling vigour in the yew (Taxus baccata L.) in England. J. Biogeography 9:55-63.

Moreno F, G A Plaza, S V Magnitsky (2006) Efecto de la testa sobre la germinación de semillas de caucho (Hevea brasiliensis Muell.). Agron. Colomb. 24:290-295.

Mosseler A, J E Major, J D Simpson, B Daigle, K Lange, Y S Spark, K H Johnsen, O P Rajora (2000) Indicators of population viability in red spruce, Picea rubens. I. Reproductive traits and fecundity. Can. J. Bot. 78:928-940.

Munive-Martínez E, O Vázquez-Cuecuecha, E M Zamora-Campos, E Fernández-Pedraza, E García-Gallegos (2008) Variación de conos y semillas de Pinus ayacahuite var. veitchii Shaw de dos procedencias del Estado de Tlaxcala. Foresta Ver. 10:39-46.

Muñoz-Gutiérrez L, J J Vargas-Hernández, J López-Upton, M SotoHernández (2009) Effect of cutting age and substrate temperature on rooting of Taxus globosa. New Forests 38:187-196.

Nicholson R, D X Munn (2003) Observations on the propagation of Taxus globosa Schltdl. Bol. Soc. Bot. Méx. 72:129-130.

Rodríguez R, Narvaez F, H Williams (1998) Calidad de la semilla de líneas e híbridos de sorgo sometidos a intemperismo. Agron. Mesoam. 9:45-50.

SAS Institute (1998) SAS/STAT Guide for Personal Computers. Version 8.0. Cary, NC, USA. 1128 P.

SEMARNAT, Secretaría de Medio Ambiente y Recursos Naturales (2002) Norma Oficial Mexicana NOM-059-ECOL-2001. Diario Oficial, 2da Sección. Protección ambiental -Especies nativas de México de flora y fauna silvestres -Categorías de riesgo y especificaciones para su inclusión, exclusión o cambio -Lista de especie en riesgo. Marzo de 2002. México, D.F. 85 p.

Shemluck, J M, E Estrada, R Nicholson, S W Brobst (2003) A preliminary study of the taxae chemistry and natural history of the Mexican yew, Taxus globosa Schltdl. Bol. Soc. Bot. Méx. 72:119-127.

Soto M, M Sanjurjo, M T Ganzález, D Cruz, F Giral (2000) El tejo mexicano (Taxus globosa Schl.), potencial de su aprovechamiento en taxol. Ciencia Ergo Sum 7:277-279.

Stanton M L (1984) Development and genetic sources of seed weight variation in Raphanus raphanistrum L. (Brassicaceae). Amer. J. Bot. 71:1090-1098.

Tenorio-Galindo G, D A Rodríguez-Trejo, G F López-Ríos (2008) Efecto del tamaño y color de la semilla en la germinación de Cecropia obtusifolia Bertol (Cecropiaceae). Agrociencia 42:585-593.

Zamudio R S (1992) Flora del Bajío y Regiones Adyacentes. Fascículo 9. Instituto de Ecología, A.C. Centro Regional del Bajío. Pátzcuaro, Michoacán, México $6 \mathrm{p}$.

Zavala Ch F (2001) Análisis demográfico preliminar de Taxus globosa Schlecht. en el Parque Nacional El Chico, Hidalgo, México. I: Población de adultos y algunas características del hábitat. Ciencia Ergo Sum 8:169-174.

Zavala Ch F (2002) Análisis demográfico preliminar de Taxus globosa Schlecht. en el Parque Nacional El Chico, Hidalgo, México. II: Población de adultos y algunas características del hábitat. Ciencia Ergo Sum 8:177-183. 